\title{
Cetacean morbillivirus in Northern and Southern Hemispheres
}

\author{
Giovanni Di Guardo ${ }^{1 *}$ and Sandro Mazzariol ${ }^{2}$ \\ ${ }^{1}$ Faculty of Veterinary Medicine, University of Teramo, Teramo, Italy \\ 2 Department of Comparative Biomedicine and Food Science, University of Padua, Padua, Italy \\ *Correspondence: gdiguardo@unite.it
}

Edited by:

Hironori Sato, National Institute of Infectious Diseases, Japan

Reviewed by:

Yukinobu Tohya, Nihon University, Japan

Keywords: Cetacean morbillivirus, stranded cetaceans, viral strains, virus-host interaction, aquatic mammals

\section{A commentary on}

Novel Cetacean morbillivirus in Guiana dolphin, Brazil

by Groch, K. R., Colosio, A. C., Marcondes, M. C. C., Zucca, D., Díaz-Delgado, J., Niemeyer, C., et al. (2014). Emerg. Infect. Dis. 20, 511-513. doi: 10.3201/eid2003.131557

Cetacean morbillivirus in coastal indo-pacific bottlenose dolphins, Western Australia

by Stephens, N., Duignan, P. J., Wang, J., Bingham, J., Finn, H., Bejder, L., et al. (2014). Emerg. Infect. Dis. 20, 666-670. doi: 10.3201/eid2004.131714

In the last 25 years, at least 10 dramatic morbilliviral epidemics have occurred among free-ranging pinniped and cetacean species and populations worldwide. The origin(s) of the new Morbillivirus genus members causing these mass mortality events, along with the reason(s) behind their "sudden" appearance among wild aquatic mammals, are still unknown (Di Guardo et al., 2005, 2011; Di Guardo, 2012).

Interestingly enough, two recent papers have reported the existence of Cetacean morbillivirus (CeMV) strains infecting wild cetaceans (Tursiops aduncus and Sotalia guianensis, respectively) in the Southern Hemisphere (Groch et al., 2014; Stephens et al., 2014) and exhibiting marked genetic differences from those infecting cetaceans of the Northern Hemisphere (Van Bressem et al., 2009; Di Guardo et al., 2011; Di Guardo and Mazzariol, 2013). Albeit quantified only for the nucleoprotein $(\mathrm{N})$ and phosphoprotein $(\mathrm{P})$ genes, these differences are so consistent that one could question the inclusion of the concerned isolates into the CeMV clade. Furthermore, the agent recovered from the two T. aduncus individuals stranded along the Western Australia coastline was deemed to be, with exclusive reference to the $\mathrm{N}$ and $\mathrm{P}$ genes, the CeMV more closely related to Measles Virus (MeV) as well as to Peste des Petits Ruminants Virus (PPRV) and Rinderpest Virus (RPV), the archetype morbillivirus (Stephens et al., 2014). Intriguingly, no peculiar inflammatory lesions nor immunohistochemical (IHC) evidence of morbilliviral antigen were observed in the brain of these two animals (Stephens et al., 2014), differently from CeMV-infected cetaceans (Di Guardo and Mazzariol, 2013; Di Guardo et al., 2013) but also similarly to experimentally RPVinfected cattle (Wohlsein et al., 1993). In this respect, while CeMV sequences could be demonstrated in the brain and lung from approximately $40 \%$ of the striped dolphins (Stenella coeruleoalba) found stranded during the first mid of 2013 along the Tyrrhenian coast of Italy, IHC evidence of morbilliviral antigen was obtained from the brain of only one of these animals (Casalone et al., 2014). Nevertheless, the isolate(s) characterized from these dolphins, apart from being identical to each other, were also very similar to those responsible for the three previous epidemic outbreaks occurred throughout the last 25 years in the Western Mediterranean (Di Guardo and Mazzariol, 2013; Casalone et al., 2014).
In conclusion, while more data are certainly needed on the genetic "make-up" of the newly discovered CeMV strains infecting cetaceans in the Southern Hemisphere (Groch et al., 2014; Stephens et al., 2014), it should be additionally emphasized that, despite the existence of single, highly valuable contributions in this field (Shimizu et al., 2013), a very limited body of knowledge is available on the host-related components as well as on the agent-related factors driving the complex Morbillivirus-cetacean interaction dynamics (Di Guardo, 2012).

\section{ACKNOWLEDGMENTS}

This work was carried out with research grants by the Italian Ministry for the Environment, under the umbrella of the Research Project "Le Sentinelle del Mare," coordinated by Prof. Giovanni Di Guardo.

\section{REFERENCES}

Casalone, C., Mazzariol, S., Pautasso, A., Di Guardo, G., Di Nocera, F., Lucifora, G., et al. (2014). Cetacean strandings in Italy: an unusual mortality event along the Tyrrhenian Sea coast in 2013. Dis. Aquat. Organ. 109, 81-86. doi: 10.3354/ dao02726

Di Guardo, G. (2012). Morbillivirus-host interaction: lessons from aquatic mammals. Front. Microbiol. 3:431. doi: 10.3389/fmicb.2012.00431

Di Guardo, G., Di Francesco, C. E., Eleni, C., Cocumelli, C., Scholl, F., Casalone, C., et al. (2013). Morbillivirus infection in cetaceans stranded along the Italian coastline: pathological, immunohistochemical and biomolecular findings. Res. Vet. Sci. 94, 132-137. doi: 10.1016/j.rvsc.2012.07.030

Di Guardo, G., Marruchella, G., Agrimi, U., and Kennedy, S. (2005). Morbillivirus infections in aquatic mammals: a brief overview. J. Vet. Med. A Physiol. Pathol. Clin. Med. 52, 88-93. doi: 10.1111/j.1439-0442.2005.00693.x

Di Guardo, G., and Mazzariol, S. (2013). Dolphin Morbillivirus: a lethal but valuable infection 
model. Emerg. Microbes Infect. 2:e74. doi: 10.1038/emi.2013.74

Di Guardo, G., Mazzariol, S., and Fernández, A. (2011). Biologically threatened dolphins and whales. Environ. Microbiol. 13, 2833-2834. doi: 10.1111/j.1462-2920.2011.02565.x

Groch, K. R., Colosio, A. C., Marcondes, M. C. C., Zucca, D., Díaz-Delgado, J., Niemeyer, C., et al. (2014). Novel Cetacean morbillivirus in Guiana dolphin, Brazil. Emerg. Infect. Dis. 20, 511-513. doi: 10.3201/eid2003.131557

Shimizu, Y., Ohishi, K., Suzuki, R., Tajima, Y., Yamada, T., Kakizoe, Y., et al. (2013). Amino acid sequence variations of signaling lymphocyte activation molecule and mortality caused by morbillivirus infection in cetaceans. Microbiol. Immunol. 57, 624-632. doi: 10.1111/1348-0421. 12078

Stephens, N., Duignan, P. J., Wang, J., Bingham, J., Finn, H., Bejder, L., et al. (2014). Cetacean morbillivirus in coastal indo-pacific bottlenose dolphins, Western Australia. Emerg. Infect. Dis. 20, 666-670. doi: 10.3201/eid2004. 131714

Van Bressem, M.-F., Raga, J. A., Di Guardo, G., Jepson, P. D., Duignan, P. J., Siebert, U., et al. (2009). Emerging infectious diseases in cetaceans worldwide and the possible role of environmental stressors. Dis. Aquat. Organ. 86, 143-157. doi: 10.3354/dao 02101

Wohlsein, P., Trautwein, G., Harder, T. C., Liess, B., and Barrett, T. (1993). Viral antigen distribution in organs of cattle experimentally infected with rinderpest virus. Vet. Pathol. 30, 544-554. doi: 10.1177/0300985893030 00608

Conflict of Interest Statement: The authors declare that the research was conducted in the absence of any commercial or financial relationships that could be construed as a potential conflict of interest.

Received: 31 March 2014; accepted: 21 April 2014; published online: 07 May 2014.

Citation: Di Guardo $G$ and Mazzariol S (2014) Cetacean morbillivirus in Northern and Southern Hemispheres. Front. Microbiol. 5:211. doi: 10.3389/ fmicb.2014.00211

This article was submitted to Virology, a section of the journal Frontiers in Microbiology.

Copyright (C) 2014 Di Guardo and Mazzariol. This is an open-access article distributed under the terms of the Creative Commons Attribution License (CC BY). The use, distribution or reproduction in other forums is permitted, provided the original author(s) or licensor are credited and that the original publication in this journal is cited, in accordance with accepted academic practice. No use, distribution or reproduction is permitted which does not comply with these terms. 